\title{
Fine needle aspiration cytology of breast lumps with histopathologic correlation in Owo, Ondo State, Nigeria: a five-year review
}

\author{
David E. Ibikunle ${ }^{1}$, John A. Omotayo ${ }^{2}$ and Olufemi O. Ariyibi ${ }^{1}$ \\ Ghana Med J 2017; 51(1): 1-5～DOI: http://dx.doi.org/10.4314/gmj.v51i1.1
}

\begin{abstract}
${ }^{1}$ Department of Histopathology, Federal Medical Centre, Owo, Ondo State, Nigeria ${ }^{2}$ Department of Anatomic Pathology, Ekiti State University Teaching Hospital, Ado-Ekiti, Nigeria.
\end{abstract}

Corresponding author: John A. Omotayo

E-mail: tunjiomotayo@yahoo.co.uk

Conflict of interest: None declared

\begin{abstract}
SUMMARY
Objective: To determine the histopathologic correlation of fine needle aspiration cytology FNAC of breast masses seen in the department of histopathology of the Federal Medical Center Owo, Southwestern Nigeria.

Design: This is a 5-year retrospective study of breast lumps seen at Department of Histopathology, Federal Medical Centre Owo, a tertiary health care facility in Southwestern Nigeria between January 12010 and December 312014.

Participants: All patients who had Fine Needle Aspiration Cytology of Breast lumps with subsequent histological confirmation over this period were included in the study.

Results: In the five years under review (2010-2014), a total of 289 FNAC of breast lumps were done. The aspirates were obtained from 275 (95.2\%) females and 14 (4.8\%) males. There were 161 cases of FNAC with corresponding tissue for histological correlation giving a biopsy rate of $55.7 \%$. The sensitivity of FNAC in determining the final histologic diagnosis was found to be $99.4 \%$ while the specificity was $100 \%$. FNAC was able to determine final histologic diagnosis conclusively in $86.3 \%$ of cases.

Conclusion: We therefore concluded that FNAC is a reliable diagnostic tool of breast lumps in our centre. Being a fast and cheap diagnostic tool as highlighted by previous studies, we advocate that clinicians should continue to embrace this diagnostic technique in the surgical management of breast lumps.
\end{abstract}

Funding: This study was entirely funded by the authors.

Keywords: Biopsy, Fine-Needle, Breast, Cytodiagnosis, Nigeria

\section{INTRODUCTION}

There is increasing awareness with associated anxiety and stress among women, who perceive every symptom in breast as cancer, compelling them to seek medical advice. It is sometimes difficult to determine whether a suspicious lump is benign or malignant simply from clinical assessment. ${ }^{1}$

Due to its increasing incidence, morbidity and mortality breast cancer is the commonest malignant tumour responsible for $18.4 \%$ of all female cancers worldwide. As it is the leading cause of death from cancer in women, ${ }^{2,3}$ the major concern of the surgeon and the responsibility of the surgical pathologist lies in the ability to differentiate a benign from a malignant lesion.

Although open surgical biopsy is the 'gold standard' for diagnosis of palpable breast lesions, in recent years two types of minimally invasive breast biopsy techniques, core needle biopsy (CNB) and fine needle aspiration cytology (FNAC), have become established for the diagnostic evaluation of palpable breast lesions. ${ }^{4}$ A triple test consisting of clinical examination, mammography and FNAC is considered the gold standard in making a definitive assessment of breast lumps. ${ }^{5}$

In resource poor settings like ours, FNAC comes readily useful for its obvious advantages. It is a cheap, fast, and reliable diagnostic method. It also reduces the frequency of open biopsies. ${ }^{5}$ Some of the setback of FNAC include pain and haematoma formation. It has also been found to have the potential to mask radiological assessment when done prior to mamography. ${ }^{4}$ It is also possible that the smears may be acellular (no cells are harvested) making cytological analysis impossible. These are described as inadequate aspirates and rates vary markedly, being particularly operator dependent and cases have to be converted to $\mathrm{CNB}$ which is able to solve the problem. ${ }^{6,7}$ 
We therefore set out to publish our experience in the last five years of operating a functional FNAC clinic of the breast in the Federal Medical Centre, Owo, Nigeria. From our findings, we determine the correlation between the results of our breast FNAC and corresponding tissue biopsy and consequently determine the accuracy of our FNAC reporting.

\section{METHODS}

This is a retrospective study conducted at Department of Histopathology, Federal Medical Centre, Owo between January 12010 and December 31 2014. All patients who had FNAC of breast lumps with subsequent histological confirmation over this period were included in the study.

Fine needle aspirations were done by pathologists using between $10 \mathrm{ml}-20 \mathrm{ml}$ syringe with $23 \mathrm{G}$ needle. Smears were stained with Haematoxylin and Eosin $(\mathrm{H} \& \mathrm{E})$, Papanicolaou and Giemsa stains.

The cytological diagnoses were then categorized into one of five diagnostic categories in accordance with the recommendations of the United Kingdom National Health Services Breast Screening Programme (NHSBSP). ${ }^{3}$

The cases were reported using a modification of the NHB reporting criteria

C 1 - Insufficient cells for cytological analysis, i.e. fewer than five epithelial cell groups,

C2 - Cells present all benign; no suspicious features,

C3 - Cells suspicious but probably benign,

C4 - Cells suspicious but probably malignant and

C5 - Definitely malignant.

With this diagnostic protocol, the surgical pathologist is able to demonstrate some degree of diagnostic certainty and that the surgical pathologist is able to advise the surgeon to plan the patient for major breast surgery on the basis of the cytological diagnosis alone. ${ }^{6}$

Histopathological slides of corresponding cytological cases were correlated. Based on these findings, the sensitivity, specificity, positive predictive value and negative predictive value of Fine Needle Aspiration Cytolo$\mathrm{gy}$ as a test were calculated.

\section{Ethical approval}

Ethical approval for this study was obtained from the Ethics and Research committee of the Federal Medical Centre, Owo, Nigeria. An ethical clearance certificate No. FMCO/662015 was issued for the study.

\section{RESULTS}

A total of 289 FNAC were done during the study period. These were obtained from 275 (95.2\%) females and $14(4.8 \%)$ males, giving a male to female ratio of $1: 19$. The right breast was more affected in $146(50.1 \%)$ cases, left breast in $118(40.8 \%)$ cases and bilateral in the remaining 25(8.7\%) cases. In 161 cases, tissue biopsies were done giving a biopsy rate of $55.7 \%$. The diagnosis of the FNAC as obtained in the NHSBSP guideline is given in Table 1 for the total 161 cases that were included in our study.

\section{Table 1 Comparison of FNAC and Histologi-} cal diagnosis

\begin{tabular}{|l|l|l|l|}
\hline Category & Diagnosis & $\begin{array}{l}\text { FNAC } \\
\text { Number (\%) }\end{array}$ & $\begin{array}{l}\text { Histology } \\
\text { Number (\%) }\end{array}$ \\
\hline C1 & Insufficient & $2(1.2)$ & - \\
C2 & Benign & $98(60.9)$ & $113(70.2)$ \\
C3 & $\begin{array}{l}\text { Suspicious probably } \\
\text { Benign }\end{array}$ & $14(8.7)$ & - \\
\hline C4 & Suspicious probably & $6(3.7)$ & - \\
\hline C5 & Malignant & & \\
Total & Malignant & $41(25.5)$ & $48(29.8)$ \\
\hline
\end{tabular}

FNAC was able to make correct definitive diagnosis in 139 cases $(86.3 \%)$. All 98 cases diagnosed as Benign (C2) and those diagnosed as malignant (C5) (41 cases) ended up as benign and malignant respectively on histologic examination.

Diagnoses of malignancy were confirmed histologically on all $41(100 \%)$ cases diagnosed as malignant on FNAC, all six (6) cases (100\%) diagnosed on FNAC as suspicious possibly malignant, and one (1) $(7.1 \%)$ of cases diagnosed as suspicious possibly benign on FNAC. There was no case diagnosed as benign on FNAC that ended up being malignant on histology.

All $98(100 \%)$ cases diagnosed as benign on FNAC ended up being benign on histology while 13(92.9\%) out of the 14 cases diagnosed as suspicious possibly benign also turned out to be benign on histology. The two cases that were classified as inadequate for evaluation on FNAC were also found to be benign on histology. There were no cases of suspicious possibly malignant (C4) or straight forward malignant (C5) on FNAC that came out to be benign on histology.

Positive FNAC will mean cases in which FNAC was able to detect correctly the final histologic diagnosis while negative FNAC are those where final histologic diagnosis were at variance with initial FNAC diagnosis. 
For the purpose of proper statistical analysis, cases diagnosed as $\mathrm{C} 4$ and $\mathrm{C} 5$ were stratified together as malignant while $\mathrm{C} 2$ and $\mathrm{C} 3$ were designated benign.

We calculated the sensitivity and specificity of FNAC as a diagnostic procedure for breast masses, positive and negative predictive value of FNAC as a diagnostic procedure for the entire study.

Table 2 Table of comparison of FNAC sensitivity with histology (gold standard)

\begin{tabular}{llllll} 
& & \multicolumn{3}{c}{ HISTOLOGY } \\
\multirow{2}{*}{ FNAC } & POSITIVE & 158 & 0 & $\mathbf{1 5 8}$ \\
& NEGATIVE & 1 & 2 & $\mathbf{3}$ \\
& TOTAL & $\mathbf{1 5 9}$ & $\mathbf{2}$ & $\mathbf{1 6 1}$ \\
\hline
\end{tabular}

Sensitivity (Table 2) of FNAC is the ability of a test to identify correctly all those who have the disease Sensitivity $=[$ True positive $/$ (True positive + false negative $)]$ $\times 100 \%$

$$
\begin{aligned}
& =[158 /(158+1)] \times 100 \%=158 / 159 \times 100 \% \\
& =99.4 \% .
\end{aligned}
$$

The specificity of FNAC is the ability of the study to identify correctly the candidates who do not have the disease.

Specificity $=[$ True Negative $/$ (True Negative + False positive $)] \times 100 \%$

$$
=[2 /(2+0)] \times 100=100 \% \text {. }
$$

The positive predictive value (PPV) of FNAC was calculated as the probability that the patient with a positive test has the disease in question. From this study this is calculated as:

PPV $=[$ True Positive $/$ (True Positive + False Positive) $] \times 100 \%$

$$
=[158 /(158+0]) \times 100=100 \% \text {. }
$$

The negative predictive value (NPV) of FNAC is the probability of a patient with a negative test not having the disease in question (malignancy). In this study this is:

NPV $=[$ True Negative $/$ (True Negative + False Negative) $] \times 100 \%$

$$
=[2 /(2+1)] \times 100 \%=66.7 \% \text {. }
$$

The earliest large scale use of Fine Needle aspiration Cytology FNAC as a diagnostic tool in the management of palpable masses was recorded in Memorial Hospital, New York, United States in the 1930s but it did not gain much encouragement in United States during the ensuing years. The technique had resurgence in Scandinavia during the 1950s and 1960s, where it flourished before spreading to other parts of the world. ${ }^{8}$

True FNAC for breast aspirations were first introduced in the beginning of 1960s by Franzen and Zajicek at the Karolinska Hospital in Stockholm. ${ }^{9}$ Being an oncologist, Franzen introduced standard May-Grunwald Giemsa stains on air-dried smears to allow for rapid interpretation. Despite their success, it was not until 1980s that FNAC became widely used. The reasons included lack of confidence in the sensitivity and specificity of the procedure, fear of tumour implantation in the needle track, lawsuits, and surgeons not willing to relinquish the use of histological biopsy technique. ${ }^{10}$

FNAC of the breast is commonly used as part of the diagnostic triad, which in addition to FNAC includes clinical breast examination and radiological evaluation (mammography and ultrasonography). The diagnostic accuracy is close to $100 \%$ when all three modalities favour a benign or malignant diagnosis. ${ }^{11}$

Open surgical excision biopsy remains the diagnostic "gold standard" to which other methods must be compared, with almost $100 \%$ sensitivity. ${ }^{12}$ However, compared to FNAC and CNB, excision biopsy is expensive and associated with a greater degree of patient morbidity. Open biopsy leaves a visible scar that is cosmetically undesirable and may complicate mammographic follow up. In addition, open biopsy is associated with a significantly longer "turn -around" time than that which accompanies FNAC. ${ }^{13}$

The "ideal" method of biopsy to diagnose breast cancer is debatable and should depend on the expertise available in the unit, as well as the physical characteristics of the lump. FNAC is a reliable and relevant method for the pathological diagnosis of breast carcinoma in a developing nation like Malaysia. It is highly useful as an initial method of pathological assessment for palpable breast lumps. If the initial FNAC is inadequate, CNB can be a useful second line method of pathological diagnosis. Excision biopsy should be the last option to obtain a pathological diagnosis. ${ }^{13}$

The sensitivity and specificity of the results have made management of breast lumps easier for the surgeon and

\section{DISCUSSION}


more beneficial to the patients. From the literature, the sensitivity ranges from $80 \%$ to $98 \%$ and the specificity may be up to $100 \% .^{14,15,16,17}$ There are some difficulties and limitations that need to be mentioned about FNAC. Both false-negative and false-positive results can occur. ${ }^{18}$ The most significant difficulty in making a diagnosis is the overlapping features of different lesions. ${ }^{19}$

Dysplasia also has a role in the false negative results. ${ }^{20}$ Small size of the tumour cells in certain histological types (lobular carcinoma, mucinous, tubular or medullary carcinoma) may contribute to false negative results. Fine Needle Aspiration Cytology has been said to be able to give a definitive one stop assessment of a breast lump in about $90 \%$ of cases. ${ }^{1,4}$ From our study, definitive diagnosis was available in 139 out of 161(86.3\%) of cases excluding cases in $\mathrm{C} 1, \mathrm{C} 3$ and $\mathrm{C} 4$. If we add the suspicious cases (which return 95\% accuracy) to the number, the total number of cases with correct FNAC evaluation would rise up to $98.1 \%$.

In cases where after a repeat sampling, one still gets acellular aspiration or suspicious/atypical cells, then a core needle biopsy is advised which in most instances will resolve the problem. Our experience over the past 5 years is similar to that of other centres in resource poor settings. ${ }^{3,4,7}$ The fact that breast FNAC is cheap, highly sensitive and specific and has a fast turn-around time had endeared the surgeons to this mode of diagnosis.

In Egypt, a study was carried out to evaluate the efficacy of ultrasound guided FNACs by comparing the results with the corresponding definitive histological examination outcome as in our study. They also investigated the role that core needle biopsy can play as a complementary diagnostic tool for breast cancer in selected cases. The specificity and sensitivity of FNAC were $99.3 \%$ and $96.7 \%$, respectively. The overall positive predictive values and negative predictive values were $99.3 \%$ and $96.7 \%$, respectively. Aiming to maximize the preoperative diagnosis of cancer, they concluded therefore that it would be cost efficient and time saving to use FNAC as a first-line investigation to benefit from the wealth of cytological information yielded, followed by CNB in selected cases. ${ }^{7}$

FNAC has become more reliable in the diagnosis of biological behaviour of breast masses. Although its use has led reduction in the use of frozen-section histology by about $80 \%$, erroneous diagnosis is still commoner with FNAC than with histopathology. ${ }^{21}$

\section{CONCLUSION}

FNAC is a reliable, fast and accurate diagnostic method for the assessment of breast lumps. It has few manageable complications and can be done on outpatient basis.

It is our conclusion therefore that the surgeons and pathologists should continue to deploy the procedure towards the early detection of breast cancer. This will also significantly reduce patient's waiting time for incision/excision biopsy.

\section{REFERENCES}

1. Yong WS, Chia KH, Poh WT and Wong CY. A comparison of trucut biopsy with fine needle aspiration cytology in the diagnosis of breast cancer. Singapore Med J. 1999; 40(9) : 587-589.

2. Rahman MZ, Islam S. Fine Needle Aspiration Cytology of Palpable Breast Lump: A Study of 1778 Cases. Surgery S12:001. doi: 10.4172/21611076.S12-001.

3. Obaseki DE, Olu-Edo AN, Ogunbiyi JO. Diagnostic accuracy of fine needle aspiration cytology of palpable breast masses in Benin City, Nigeria. West Afr J Med. 2010; 29(4):259-262. PubMed.

4. Ukah CO, Oluwasola OO. The clinical effectiveness of fine needle aspiration biopsy in patients with palpable breast lesions seen at the University College Hospital, Ibadan, Nigeria: A 10-year retrospective study. J Cytol. 2011; 28(3): 111-113.

5. Jindal U, Singh K, Kochhar A. Fine Needle Aspiration Cytology of Breast Lumps with Histopathological Correlation: A Four Year and eight month study from rural India. Internet $J$ Pathol. 2012; 13(3).

6. Walker SR. A randomized controlled trial comparing a $21 \mathrm{G}$ needle with a $23 \mathrm{G}$ needle for Fine needle aspiration of breast lumps. $R$ Coll. Surg. Edinb., 1998; 43 : 322-323.

7. Abdel-Hadi M, Abdel-Hamid GF, Abdel-Razek N, Fawzy RK. Should fine-needle aspiration cytology be the first choice diagnostic modality for the assessment of all nonpalpable breast lesions? The experience of a breast cancer screening center in Alexandria, Egypt. Diagn Cytopathol. 2010; 38(12) : 880-889.

8. Das DK. Fine Needle aspiration Cytology: Its origin, development and present status with special reference to a developing country, India. $D i$ agn Cytopathol. 2003; 28(6) : 345-351.

9. Franzen S, Zajicek J. Aspiration biopsy in the diagnosis of palpable lesions of the breast: Critical review of 3479 consecutive biopsies. Acta Radiol Ther Phys Biol. 1968; 7 : 241-262.

10. Berner A, Torill Sauer T. Fine-needle Aspiration Cytology of the Breast. Ultrastruct Pathol. 2011; 35(4) : 162-167. 
11. Wells CA, Ellis IO, Zakhour HD, Wilson AR. Editorial Working Party, Cytology Subgroup of the National Coordinating Commitee for Breast Cancer Screening Pathology. Guidelines for cytology procedures and reporting on fine needle aspirates of the breast.

Cytopathol. 1994; 5(5) : 316-334.

12. Pruthi S. Detection and evaluation of a palpable breast masses. Mayo Clin Proc. 2001; 76 : 641648.

13. Tham T-M, Iyengar KR, Taib NA, Yip C-H. Fine Needle Aspiration Biopsy, Core Needle Biopsy or Excision Biopsy to Diagnose Breast Cancer Which is the Ideal Method? Asian Pacific J Cancer Prev. 2009; 10: 155-158.

14. Wilkinson EJ, Bland KI. Techniques and results of aspiration cytology for diagnosis of benign and malignant diseases of the breast. Surg Clin North Am. 1990; $70: 801-13$.

15. Ellis IO, Galea M, Broughton N, Locker A, Blamey RW, Elston CW. Pathological prognostic factors in breast cancer. II, Histological type. Relationship with survival in a large study with long term follow up. Histopathology. 1992; 20: 479-89.
16. Edward J, Kirby I, Bland. Techniques and results of aspiration cytology for diagnosis of benign and malignant diseases of the breast. Surg Clin North Am. 1990; $70: 801$.

17. Gukas ID, Nwana EJC, Ihezue CH, Momoh JT, Obekpa PO. Tru-cut biopsy of palpable breast lesions: A practical option for pre operative diagnosis in developing countries. Cent Afr J Med. 2000; 46(5): 127-30.

18. Bukhari MH, Arshad M, Jamal S, et al. Use of fine-needle aspiration in the evaluation of breast lumps. Patholog Res Int. 2011; 2011 : 689521.

19. Bakhos R, Selvaggi SM, DeJong S, Gordon DL, Pitale SU, Herrmann M, Wojcik EM. Fine-needle aspiration of the thyroid: rate and causes of cytohistopathologic discordance. Diagn Cytopathol. 2000; 23(4) : 233-237.

20. Homesh NA, Issao MA, El-Sofiani HA. The diagnostic accuracy of fine needle aspiration cytology versus core needle biopsy for palpable breast lumps. Saudi Med J. 2005; 26(1) : 42-46.

21. Rahman MZ, Sikder AM, Nabi SR. Diagnosis of breast lump by fine needle aspiration cytology and mammography. Mymensingh Med J.2011; 20(4):658-64. 